\title{
Management of Flood-Based Farming in Guguf, Northern Ethiopia
}

\author{
Girmay A. ${ }^{1 *} \quad$ Tesfaalem G. ${ }^{2} \quad$ Abebe G. ${ }^{3} \quad$ Misgina G. ${ }^{2}$ \\ 1.Department of Geography and Environmental Studies, Raya University, Maichew, Ethiopia \\ 2.Department of Geography and Environmental Studies, Mekelle University, Mekelle, Ethiopia \\ 3.Departments of Geography and Environmental Studies, Aksum University, Aksum, Ethiopia
}

\begin{abstract}
Spate irrigation is the source of moisture for crop production in the semi-arid lowlands of Raya Valley. Despite its higher potential to suport rainfed agriculture, management of flood based farming has received less emphasis. Thus, the study attempted to examine the management of floods across the Guguf irrigation schemes. Survey data were collected from 78 households selected using systematic sampling in 2018. Data were analyzed using desriptive statistics, Chi- square and one-way ANOVA. Results showed that the participation of every farmer in the operation and maintenance activities is mandatory to receive flood. The rule of water distribution based on individual farmer's contribution helps to mobilize the minimum labor required to run the spate system. Frequent operation and maintenance activities carried out in upstream canals due to erosive flashy floods. The effect of scheme location was significant overall, $F(2,75)=24.42, p=0.000, \eta^{2}=.48$. Maize planted in Kusra, the lower scheme, has failed during its early growth stage more clarify the situation. Despite the location based flood water distribution among primary canals, distribution within the canal starts first by drawing lottery among the head, middle and tail users. In using the flood, users gradually developed different traditional water rights and distribution rules including the rule for operation and maintenance of the spate system. Instead of the present location based flood distribution that favors to farmers at the head of the spate system, even a small flood can be sufficient if allocated based on crop type and growth stage.
\end{abstract}

Keywords: Guguf, management, flood-based farming, allocation, Northern Ethiopia

DOI: $10.7176 / \mathrm{JAAS} / 61-02$

Publication date: February $29^{\text {th }} 2020$

\section{Introduction}

Water is the most dependable natural resource (Abrha, 2006; Wani et al., 2003). Most notably, access to safe and sufficient water is a basic human right. However, in arid and semi-arid areas, water is scarce. Moreover, allocation of this scarce resource is a major challenge for people living in these areas (Abraham Mehari, 2007). According to David and Ploeger (2014) approximately 2.8 billion people live in river basins affected by physical water scarcity.

Spate irrigation is a direct way for farmers to cope with water stress (Ajani, 2013; FDRE, 2002). Spate irrigation systems solve local problems and run natively through which local resources are used to decrease cost of irrigation infrastructures and cause local societies capable (Habtu and Yoshinobu, 2006). In many environmentally marginal areas ranging from arid to semi-arid areas of mainly Africa and Asia where spate irrigation flourish (Briggs 2005; Mehari et al 2005), there are often insufficient scientific answers available to overcome local problems with the resources available (Morgan et al., 2012). Feasibility studies also suggest that spate irrigation can support many farmers in many irrigable areas (Ham, 2008; Negash et al., 2019).

Spate irrigation is practiced in many semi-arid lowlands of Ethiopia. These practices have been playing a vital role in improving the livelihood of farmers in the country. However, the existing community managed spate irrigation systems face various problems related to water management, water allocation among the upstream, mid and downstream users and loss of water in irrigation systems which have reduced the benefits that could have been harvested (Nazari et al. 2018).

The low-lying areas settlers of Guguf stream highly rely on management of floods generated from the surrounding mountains for their livelihood. Water relief and drainage is also a critical problem in the area. Despite this, the flood water management and distribution system was not addressed in detail. Therefore, the main objective of the study is to examine the management and allocation of spate water across the Guguf stream schemes of the Raya Valley, Ethiopia.

\section{Materials and Methods}

2.1 Study area

The Gugf catchment is geographically located between $12^{\circ} 42^{\prime}-12^{\circ} 49^{\prime} \mathrm{N}$ latitudes and $39^{\circ} 31^{\prime}-39^{\circ} 45^{\prime} \mathrm{E}$ longitudes. Guguf stream originates from the high lands of Enda Mokoni district including mountain Tsibet, the highest mountain in the northern region, Tigray. The altitude of the Guguf catchment ranges between 1523 and 3055 m.a.s.l. Figure 1 shows the geographical location of the study area. 


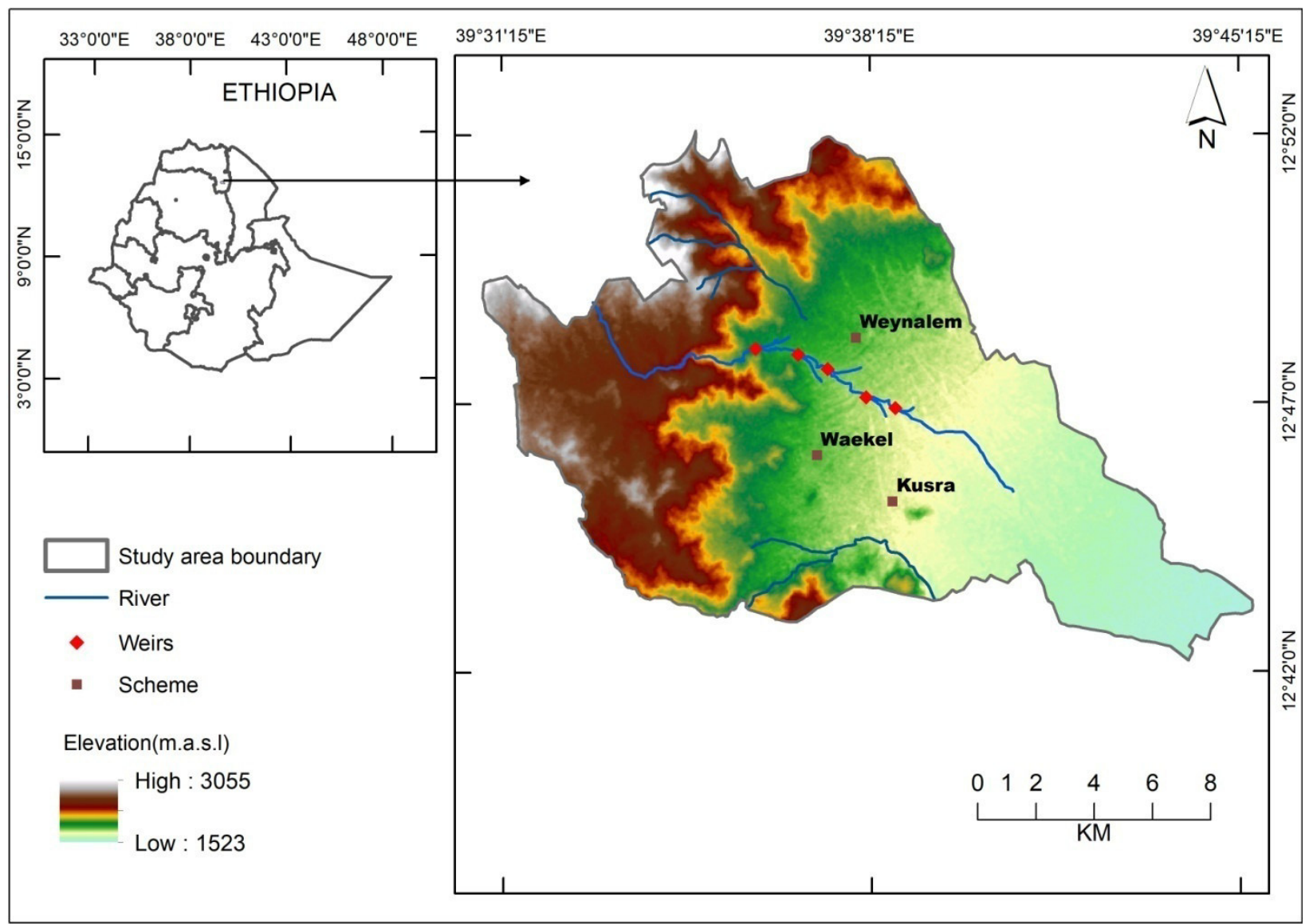

Figure 1: Location of the study area Produced Using ArcGIS 10.3

The upper watershed, which is characterized by steep mountains of high elevation and gently sloping hills is the dominant supplier of water, sediment and nutrients for the low-lying Guguf River irrigated fields. Weynalem, Waekel and Kusra are the three schemes in the upper, middle and lower reach of Guguf River respectively. The catchment has an average annual rainfall of $683.2 \mathrm{~mm}$ and an average annual temperature of $21.5^{\circ} \mathrm{c}$ (NMA, 2017).

In general, two rainfall seasons can be observed in the study area: little rains (Belg), which generally occurs from March to May, and the summer (Kiremt) that take place from June to September. Irregularity of the rainfall distribution within a growing season and variability of onset and offset of the rainy seasons are main constraints for the dry land crop production. Thus, the farmers in the study area manage flood to compliment rainfed agriculture. The spate irrigation system under Guguf stream is one of the ancient irrigation areas in the region which covers 650 ha. (Haile et al., 2013). This ephemeral stream water is used for irrigation, drinking and other domestic purposes. The spate flow from the stream supplies many command areas in Raya Valley. However, the flood decreased by $0.23 \times 10^{6} \mathrm{~m}^{3} \mathrm{yr}^{-1}$ from 1980-2015 (Negash et al., 2019) making its management difficult. The spate flow from Guguf supplied Weynalem, Waekel, and Kusra schemes. Each scheme has different diversion weir (Figure 1), main diversions (Maegels) and canals (Melwen) to convey water to the field. The three schemes under Guguf irrigation have share management arrangements in common and govern their respective diversions. The schemes are named by their near villages where most irrigators are located.

\subsection{Materials and Methods}

Survey design was employed to investigate the management of the spate system. Field observation and focus group discussion methods were also employed for collecting qualitative data. The number of beneficiary households of the schemes of Guguf were 800 (Haile et al. 2013) of which about one third were female-headed households. As shown in Table1 it can be observed that the number of irrigator households was higher in Waekel (21\%) scheme and lower in Kusra scheme (12\%) which may indicate at the downstream (Kusra scheme) the flood is not reliable while at the top stream (Weynalem scheme) it may be erosive to divert. 
Table 1. Total and sample households

\begin{tabular}{lllllrrrr}
\hline Sample & \multicolumn{4}{c}{ Total households* } & \multicolumn{4}{c}{$*$ Sample households } \\
\cline { 2 - 9 } Site & Male & Female & Total & $\%$ & Male & Female & Total & $\%$ \\
\hline Weynalem & 247 & 40 & 287 & 36 & 24 & 4 & 28 & 36 \\
Waekel & 278 & 50 & 328 & 41 & 27 & 5 & 32 & 41 \\
Kusra & 153 & 32 & 185 & 23 & 15 & 3 & 18 & 23 \\
\hline Total & 678 & 122 & 800 & 100 & 66 & 12 & 78 & 100 \\
\hline
\end{tabular}

Source: *Haile et al $2013 ; * *$ Computed from target population, 2018

Sample size can be determind using published tables, based on precision, confidence levels, and variability (Israel 2018). Thus, the required sample size of the study was estimated to be 78 households. $10 \%$ of the irrigators from all the three schemes were selected proportionally. First Weynalem, Waekel and Kusra schemes were purposefully selected. Next households were selected using systematic sampling. The $\mathrm{K}^{\text {th }}$ household head was selected using the formula $\mathrm{K}=N / n$. Where $\mathrm{K}$ is the $\mathrm{K}^{\text {th }}$ household from the list, $\mathrm{N}$ is the total number of households across the system and $\mathrm{n}$ is sample size from each scheme surveyed.

Questionnaire was administered to 78 respondents. Questions were pretested on 30 respondents (10 female and 20 male) before the commencement of the main. The pretesting was done in Burqa spate irrigation scheme which has similar irrigation practice with the study area. The reliability of the questionnaire was found to be 0.82 indicating high correlation of responses among farmers. Questionnaire was used to gather data about operation and maintainance and sharing of irrigation water among users regarding number of hours' spate flow is allotted. Water users and managers were interviewed for seeking clarifications on sharing of water within and among the upstream, midstream and downstream categories of irrigators.

Focus group discussion was conducted with irrigation water managers and farmers to understand distribution of spate irrigation deeply. There were three formal discussion groups (one from each scheme) sized between six and eight. Group composition considered age and sex. The irrigated land, diversion structures and irrigation canals were also observed to cross check the information obtained through interviews. Moreover, photos were taken to show general overview of the irrigation scheme. Detailed description of enforcing allocation rights and rules and distribution of flood water among users were recorded based on field observation, survey and secondary documents.

This study used both qualitative and quantitative analysis techniques. Qualitative data were analyzed thematically through concept analysis technique. Percentages, frequencies, mean and standard deviation using statistical package for social science (SPSS) version 20 software were employed to summarize the numerical data. One-way Analysis of Variance (ANOVA) was conducted to examine the distribution of flood water (in hours) among user farmers of the schemes.

\section{Results and Discussions}

\subsection{Operation and maintenance of water distribution structures}

The core processes of irrigation practices include control, allocation, and distribution of water and make it available for crop growing (Lawrence et al., 2005). In doing so, water control structures provoke a particular type of water allocation and distribution practices. In Guguf irrigation system, the operation and maintenance work is organized by the water management committee of each respective scheme. During operation and maintenance works the beneficiary community rehabilitates all the communal structures. The structures rehabilitated by shared labor include diversion head (weir), diversions and canals (Table 2). The operation and maintenance of field canals of each plot is the responsibility of individual farmer.

For the purpose of eased management of each group in the spate irrigation system, there are Abo-Mai (water masters) who deputy their respective groups and have the responsibility to organize the farmers under their group for sharing of spate water and mobilize labor and material for regular and emergency operation and maintenance activities. As indicated in Table 2, the frequency and type of operation and maintenance activities vary significantly among the three schemes of Guguf SIS.

In Weynalem scheme $57 \%$ of the sampled farmers responded they were engaged in operation and maintenance of diversion and weir greater than 7 times during the rainy season whereas about $28 \%$ and $7 \%$ responds 4-6 times and 1-3 times respectively. These operation and maintenance activities at the diversionin including diversion weir and canals were mostly focused on the clearing of sedimentation from the hydraulic structures. The excavation of the secondary canals and construction of the field bund were also performed.

$7.14 \%$ of the respondents in Weynalem do not participated in maintenance of diversions. Results of the focus group discussion in Weynalem scheme revealed that females were not enforced to participate in maintenance activities if they have no available male labor. However, in Waekel scheme females were fined to contribute daily labor wage at times of operation and maintenance activities. As shown in Table 2, in Waekel scheme $51.56 \%$ and $32.82 \%$ of the respondents engaged in operation and maintenance of diversion and canal 4-6 
times and greater than 7 times respectively.

Table 2. Frequency of participation in operation and maintenance activities

\begin{tabular}{llcccccc}
\hline \multirow{2}{*}{$\begin{array}{l}\text { Scheme } \\
\text { Name }\end{array}$} & Farmers participation in & \multicolumn{2}{c}{ Diversion \& weir } & \multicolumn{2}{c}{ Canal } & \multicolumn{3}{c}{ Average } \\
\cline { 2 - 8 } & maintenance & Number & $\%$ & Number & $\%$ & Number & $\%$ \\
\hline \multirow{3}{*}{ Weynalem } & 1-3 Times & 2 & 7.14 & 15 & 53.6 & 8.5 & 30.37 \\
& 4-6 Times & 8 & 28.58 & 9 & 32.1 & 8.5 & 30.34 \\
& >=7 Times & 16 & 57.14 & 4 & 14.3 & 10 & 35.72 \\
& Never & 2 & 7.14 & 0 & 0.0 & 1 & 3.57 \\
& Total & 28 & 100 & 28 & 100 & 28 & 100 \\
\hline \multirow{3}{*}{ Waekel } & 1-3 Times & 5 & 15.62 & 5 & 15.62 & 5 & 15.62 \\
& 4-6 Times & 19 & 59.38 & 14 & 43.75 & 16.5 & 51.56 \\
& >=7 Times & 8 & 25 & 13 & 40.63 & 10.5 & 32.82 \\
& Never & 0 & 0.0 & 0 & 0.0 & 0 & 0 \\
Kusra & Total & 32 & 100 & 32 & 100 & 32 & 100 \\
\hline & 1-3 Times & 9 & 50 & 7 & 38.9 & 8 & 44.45 \\
& 4-6 Times & 2 & 11.1 & 4 & 22.2 & 3 & 16.65 \\
& >=7 Times & 0 & 0.0 & 0 & 0.0 & 0 & 0 \\
& Never & 7 & 38.9 & 7 & 38.9 & 7 & 38.9 \\
& Total & 18 & 100 & 18 & 100 & 18 & 100 \\
\hline
\end{tabular}

Source: Survey result, 2018

Table 2 also showed that, $50 \%$ of the farmers who were participating in Kusra scheme involved in diversion maintenance activities 1-3 times. Yet $38.9 \%$ of the respondents never participated in operation and maintenance activities. This is more likely due to farmers in the tail end face shortage of flood hence no maintenance burden. $53.6 \%$ of the farmers' in Weynalem responded, they were more engaged with operation and maintenance activities at the canal than that of the diversion probably due to the secondary canals of the tail end of Weynalem were earthen (Figure 2) unlike the cemented upper rich canals. The major activities performed in this scheme were removal of the sediments from diversions; canals, flood flash gate and diversion weir.

The in-depth interview of the farmers indicated that, the short and long term existence of the community spate irrigation depends on the contribution of members in operation and maintenance of the irrigation network. This requires the cohesion as well as the motivation of the users to assume the system is their own. In all the spate irrigation schemes (Section 2.1) the operation and maintenance activities is full responsibility of the beneficiary farmers. As the focus group discussions revealed, operation and all maintenance works were carried before the arrival of the rainy season. The findings of (Abraham Mehari, 2007) in Eritrea also revealed that operation and maintenance of structures contribute to the establishment of successful community based organizations that help the distribution of spate water, enforce rules and regulations, respect water turns.

The more frequency of operation and maintenance activities were carried out at the primary canal including headwork as compared to that of Waekel and Kusra schemes more likely due to the erosive and devastative flashy floods first occur at the top end of the Weynalem scheme. Results of the focus group discussion indicated that unlike in Waekel scheme females in Weynalem were encouraged to involve in spate irrigation even if they do not participate in construction of hydraulic structures.

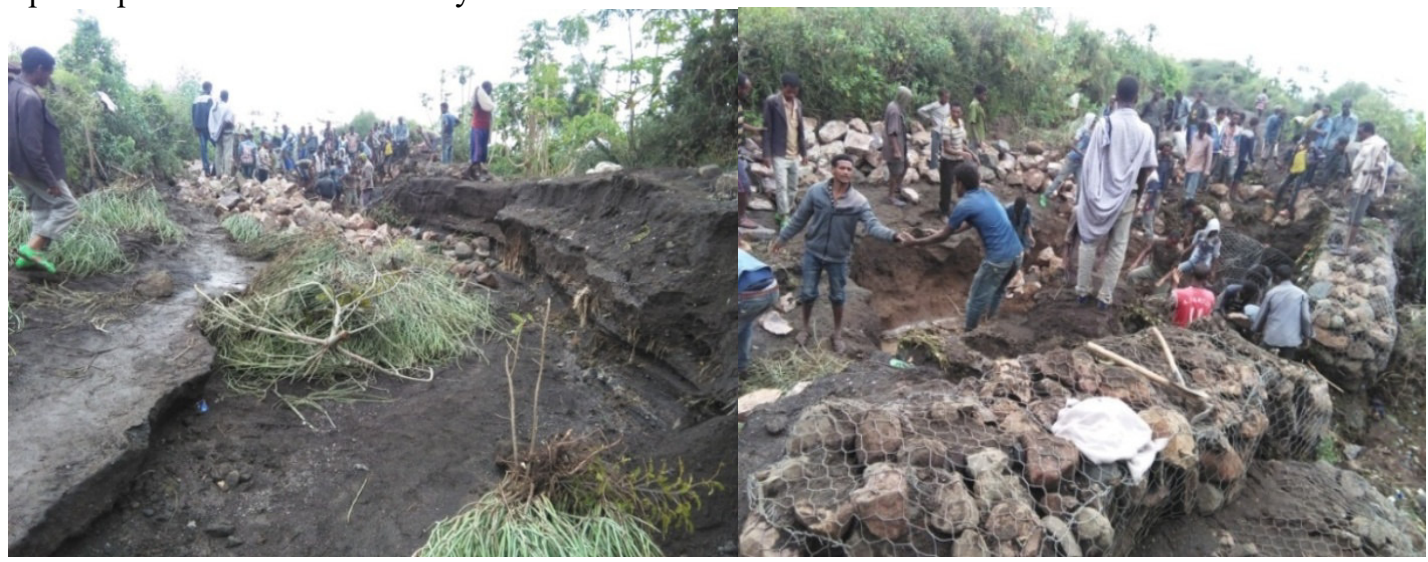

Figure. 2. Operation and maintenance work in diversion Beles at weynalem scheme

Source: Photo February 20, 2018

They are also engaged with excavation of the newly branch canals and tertiary/field canals if extension is 
necessary. For the purpose of eased management, the Weynalem and Kusra schemes Water Management Committee (WMC) organized the farmers at primary diversion (Maegel including headworks), and secondary canal (locally called Melwen). The WMC organize the farmers for sharing of spate water and mobilize labor and materials for regular and emergency operation and maintenances activities under their respective groups. However, in Waekel silt deposited in canals was removed through rented bulldozers. Farmers share the rent of the dozer which was 1500ETB per hour in 2017. Managing field bund of each plot was responsibility of the individual farmers (Figure.3c). The typical crop in the irrigable plots was sorghum (Figure. $3 \mathrm{~d}$ ) probably due to its high production and low production cost compared to teff and maize.

In the study schemes the participation of every farmer (benefiting from the system) in the operation and maintenance activities is mandatory to receive flood water. The findings of (Lawrence and van Steenbergen, 2005) were concurrent which revealed an individual farmer is entitled to getting spate water if he/ she is participating in the operation and maintenance of the headwork and flood channels. Therefore, one's claim to spate water is directly linked to the contribution made in the irrigation system. The rule of water distribution based on the contribution made by individual farmer contributes to the smooth running of the system and helps to mobilize the minimum labor required for the operation and maintenance of the spate system. This is important as farmers are dependent on one another in major operation and maintenance activities.

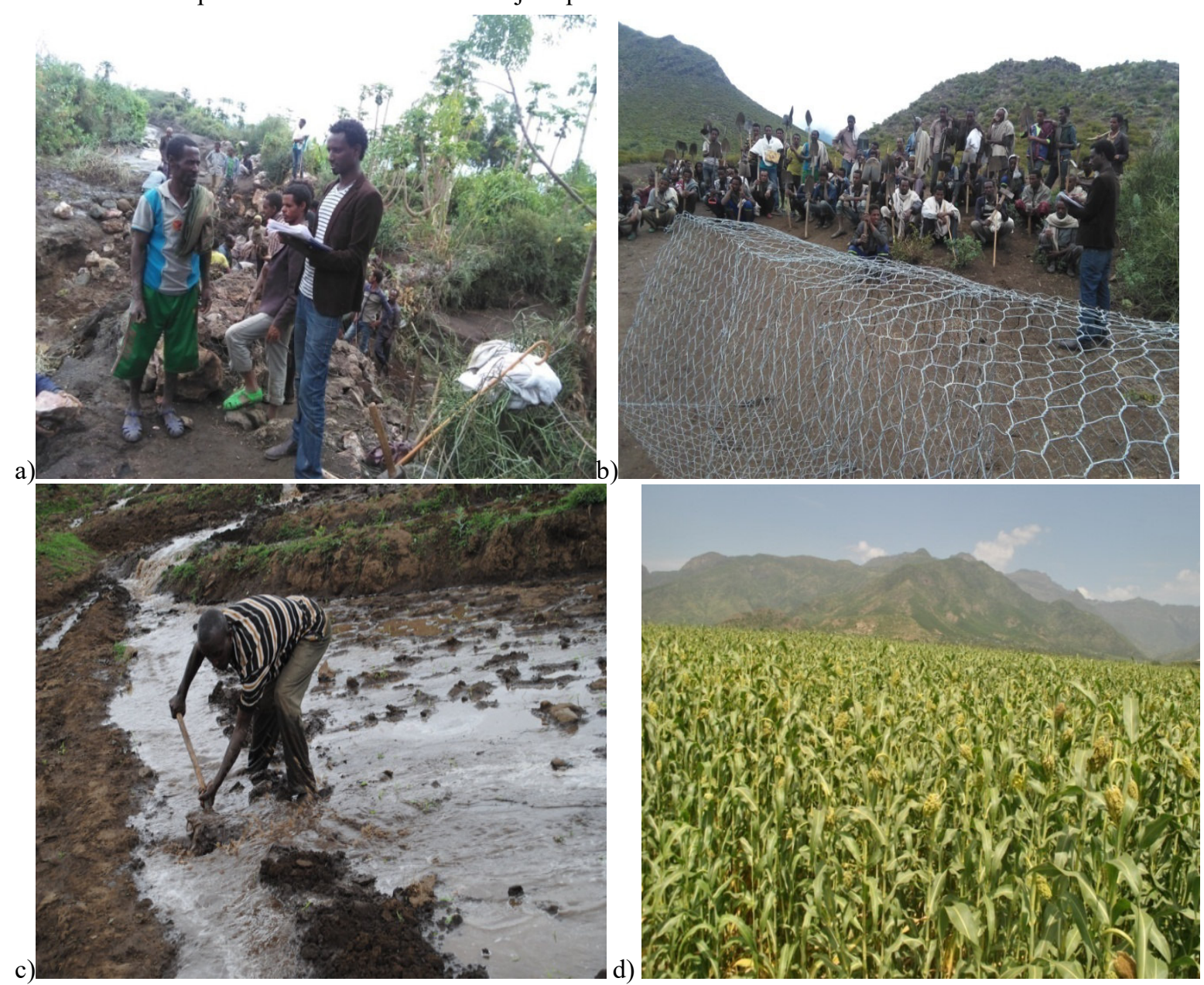

Figure 3. Farmers in operation and maintenanceof structures using local materials (a \& c), gabion (b) and dominant crop (d). Source (a\&b): Photo February 20, 2018.

Results of the focus group discussion revealed the contribution of labor for operation and maintenance depends on being part of the command area of the spate irrigation system. In routine operation and maintenance works during and before the rainy season the contribution is uniform. The contribution of labor for construction and maintenance work do not depend on land holding size and family size. But in case of emergency damage to the diversion weir and irrigation channels and urgent operation and maintenance is required before the arrival of another spate, every male adult in the irrigation beneficiary community regardless of family size is expected to mobilize to the maintenance work. The farmers can also apply to the local government (district and Tabia administration) to help mobilize additional material and labor from other communities in case the damage to the spate irrigation system is huge and cannot be urgently maintained by the beneficiary farmers before the arrival of 
the next spate. For instance in 2017 rainy season the Weynalem traditional spate irrigation main canal was broken four times near to its weir (Figure 3a).

The beneficiary farmers were unable to maintain the damage within few days. At the same time the farmers were expecting flood in the next few days. As a result, they applied to the district and Tabia administration and were able to mobilize labor from nearby communities and gabions from the District Agriculture and Rural Development Office. Most of the materials used for construction and maintenance of the spate irrigation are acquired from the localities. These materials include stone, boulders, brushwood weed plants and sand (Figure 3a). The farmers use simple hand tools during operation and maintenance works such as hoe, spade, machete (Gejera), and axes. The only external material supports gained specially in Weynalem and Waekel schemes are gabion and cement. Farmers are provided with gabions boxes to seal the broken side of the primary canals (Figure 3b)

The farmers use weed plants to seal eroded canals (field canals) and they use tree branches (brushwood), stones and sand filled sacks to maintain communal crossings. Farmers are usually occupied with maintenance works of the diversion weir and other infrastructures after almost every heavy flood. For instance, the side of the primary canal adjacent to the main river in Weynalem is usually broken by heavy spate flows (Figure 4a) which cause farmers to lose water, farmlands and deposition.
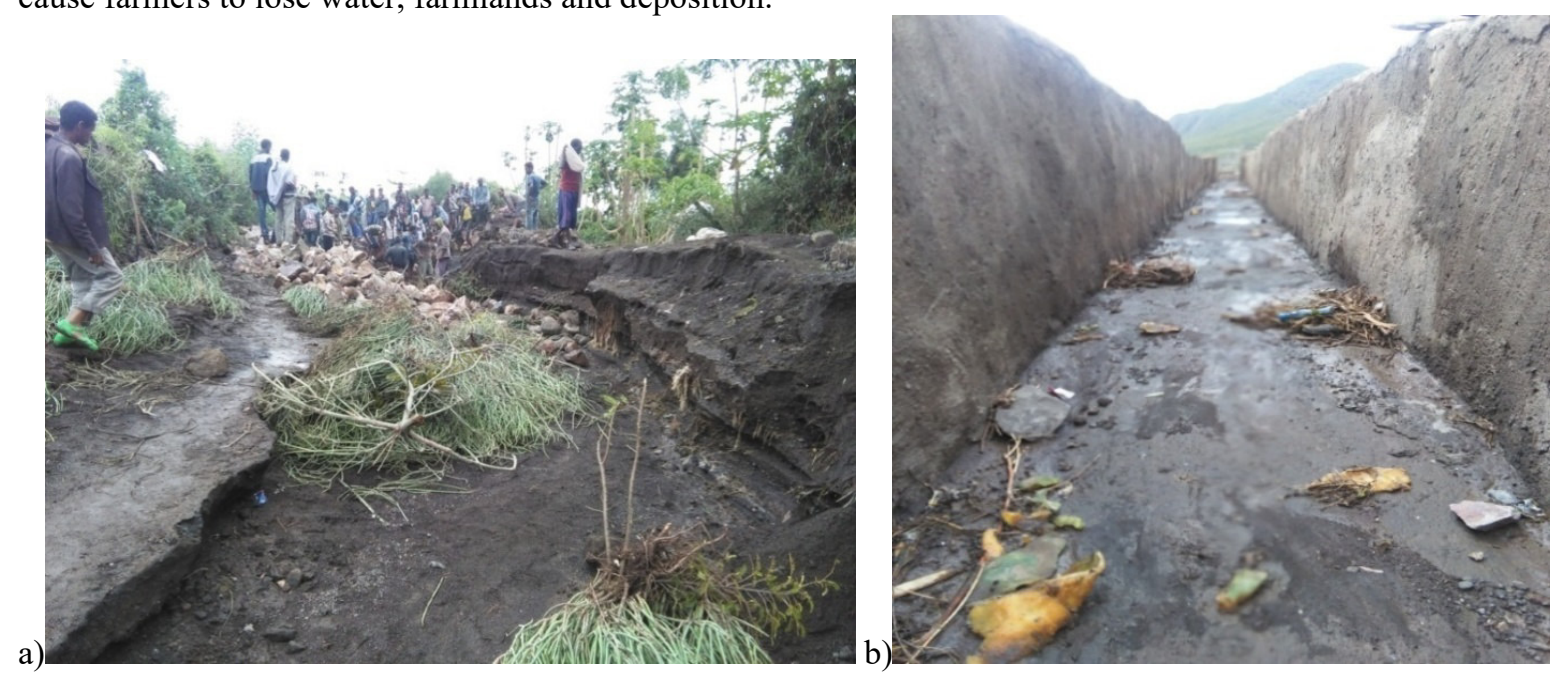

Figure 4. Earthen (a) and cemented canals (b) at Weynalem scheme

Source: Photo February 20, 2018.

In all the schemes communal work of the spate irirgation precedes individual farm activities. Farmers consider the operation and maintenance works of the spate system as part of their agricultural activities. Water distribution rules in the spate irrigation serve as a measure to ensure the mobilization of labor for maintenance of the system.

\subsection{Spate water distribution}

In Guguf spate irrigation, the spate flood is distributed through a well-laid network of primary, secondary and field canals. As flood water comes, the whole amount of water is diverted to primary canals based on their intake capacity through gated intake. Then, the amount of flood water left from the first intake passes to the next diversion intake and the process repeats starting from Weynalem scheme, then Waekel followed by Kusra. Ones the spate water is diverted, then it flows along long narrow hand dung diversions (primary canals) and divide in to the secondary canals and then field canals. When the upstream field of the command area was irrigated through the canal bund, water is released by breached canal to the downstream field bund to direct water to the next field. This process is repeated until all the fields have been irrigated. If the spate continues after all fields have been irrigated, the canal bund is then broken and the process is repeated at a bund constructed further down the diversion. Table 3 presents the distribution of Guguf stream flood across the three schemes regarding the number of hours farmers received irrigation flood in summer.

Table 3. Distribution of mean flood flow (in hours) in summer among farmers of the three schemes

\begin{tabular}{l|c|c|c}
\hline Schemes Name & Frequency & Mean hours flood flow irrigated & SD \\
\hline Weynalem & $28(36)$ & 7 & 1.58 \\
\hline Waekel & $32(41)$ & 5.5 & 1.75 \\
\hline Kusra & $18(23$ & 3.5 & 1.29 \\
\hline
\end{tabular}

Numbers in parenthesis denote percentage frequencies $\quad$ Source: Survey result, 2018

The spate flow from Guguf ephemeral stream supplied the command areas of three schemes Weynalem, 
Waekel, and Kusra schemes stream (Section 2.1). The mean hours flood irrigation used for the respondents of Weynalem scheme was 7 while for Waekel and Kusra schemes it was 5.5 and 3.5 hours respectively indicating the number of hours farmers irrigated decrease as one moves from upstream to downstream users (Table 3). The standard deviations indicated that the variations in number of irrigation hours farmers used in each scheme were similar which may indicate equitable distribution with in a scheme. A one-way analysis of variance (ANOVA) was conducted to explore the impact of farm location on seasonal (summer) total number of hours irrigation water used.

Table 4. Mean hours farmers irrigated across irrigation schemes

\begin{tabular}{lccccc}
\hline Category & Sum of squares & Df & Mean square & F & Sig \\
\hline Between groups & 130.41 & 2 & 65.24 & 24.42 & $0.000^{*}$ \\
Within groups & 192.44 & 75 & 2.56 & & \\
Total & 322.87 & 77 & & & \\
\hline
\end{tabular}

Source: Survey result, 2018. *The mean difference is significant at 0.01 level

Table 4 showed that, there was a statistically significant mean difference $\mathrm{F}(2,75)=24.42, \mathrm{p}=0.000$ at $95 \%$ confidence level) in the total number of hours irrigated per plot for the three schemes. The effect size $\left(\eta^{2}\right)$ calculated using eta squared was 0.48 . Post-hoc comparisons using the Tukey HSD test indicated that the mean number of irrigation hours a farmer irrigated for Weynalem scheme or head users (Mean=7, SD=1.58) was statistically different from Kusra scheme (Mean=3.5, SD=1.29). However, the Waekel scheme did not differ significantly from both Weynalem and Kusra. An elderly man in the focus group discussion figuratively justifies this by saying "no part of one's body never get creaming butter before the head." This analysis suggests that the distribution of flood among the three schemes was unfair. The other source of the difference among the schemes can be the capacity of the diversion and canal structures to convey sufficient spate water from the river Guguf and deliver to beneficiaries at different positions of the spate system. The findings of (Mehari et al. 2005) also revealed that, spate irrigation distribution involves certain degree of unfairness among the plots at different positions of the irrigation system due to the unpredictability of the flood flow in terms of volume and time of occurrence across the plot locations.

Table 5. Mean land holding, and mean hours farmers irrigated in Summer

\begin{tabular}{lccccc}
\hline Farm size & \multicolumn{4}{c}{ Mean } & Mean hours \\
Category & N \& \% & land (ha) & SD & Irrigated & SD \\
\hline Large & $38(48.7)$ & 1.2 & 0.07 & 6.4 & 1.09 \\
Medium & $28(36)$ & 0.74 & 0.04 & 5.6 & 1.9 \\
Small & $12(15.3)$ & 0.46 & 0.26 & 4.8 & 1.27 \\
\hline
\end{tabular}

Source: Survey result, 2018

Table 5 presents the distribution of spate flow in number of hours the sampled farmers irrigated their plot in summer in relation to farmland size. The respondents were divided into three groups according to the size of their farmland. The mean and standard deviation of farm size scores were used to categorize plots in to small; medium and large. Table 5 shows that, the mean of the large farmland category was 1.2 ha while for the medium and small categories were 0.74 ha and 0.46 ha respectively.

The farmland holding of the sampled farmers ranges from 0.25 ha (locally Tsimdi) to 1.5 ha implying the existence of large variation among the households in land ownership. The mean hours of summer flood irrigation for the respondents of the large farm size category was 6.4 hours while for medium and small farm categories the mean summer flood hours was 5.6 and 4.8 respectively.

Table 6. Number of mean hours farmers irrigated and farm size categories

\begin{tabular}{lccccc}
\hline Category & Sum of Squares & Df & Mean Square & F & Sig \\
\hline Between Groups & 46.02 & 2 & 23 & 6.234 & $0.003^{*}$ \\
Within Groups & 276.85 & 75 & 3.691 & & \\
Total & 322.87 & 77 & & & \\
\hline
\end{tabular}

Source: Survey result, 2018

* The mean difference is significant at 0.01 level

Furthermore, a one-way ANOVA between groups analysis of variance was conducted to see the impact of farmland size on the mean distribution of hours irrigation water used. Table 6 results showed that, there was a statistically significant mean difference $\mathrm{F}(2,75)=6.234, \mathrm{p}=0.003$ at $95 \%$ confidence level) in the total number of hours irrigated per plot for the three land holding size categories. The effect size calculated using eta squared was 0.43 . Post-hoc comparisons using the Tukey HSD test indicated that the mean number of irrigation hours a farmer irrigated for large farm size holders (Mean=6.4, $\mathrm{SD}=1.09$ ), Medium farm size (Mean=5.6, $\mathrm{SD}=1.9)$, and small farm size holders (Mean=4.8, $\mathrm{SD}=1.27$ ) was statistically significant (Table 5). Farmers with large farm size irrigated more they may be encouraged to invest more including involving in irrigation activities. 
3.3 Spate water distribution among canals (melwen)

In Guguf spate irrigation the flood diverted from the river bed to the primary diversions (Maegels) of the schemes is further divided in to secondary canals (locally called melwen) under each main diversion. In Weynalem scheme there are two primary diversions. The first diversion- Maegel Beles- is divided in to five canals allocated to supply spate water for groups of farmers. Similarly, at Waekel scheme there are two primary diversions. The first canal- Maegel Kokhi, a local word to indicate bedrock- is divided in to four secondary canals which are each allocated to serve four command areas (called locally Dull). The remaining diversions also have branch canals. In Kusra scheme there is one primary diversion which inturn divided in to distributery canals. The farmers in each canal are divided in to sub groups known locally as Gujile. The number of sub groups in each canal varies based on the command area (locally called dull) covered by the canal.

The purpose of dividing the canal in to Sub-groups is for the eased division of spate water to farmers at different position of the group; head, middle and tail of the canal.

The size of the flood determines the number of canals getting spate water at a time. For this reason, during the lottery draw a waiting list is reserved in case the flood is able to supply spate water to more than one secondary canal. In this case the number of secondary canals that can be supplied with flood water is decided by the water committee based on the flood size during flood occurrence. The distribution of large floods to more than one secondary canal has two advantages. First it helps to irrigate more land and second it reduces the damage that would have been caused to the channels of the spate network. The canals are situated at different positions and distance with reference to the diversion weir and the primary canals of the spate irrigation system. Though each canal receives spate water based on the predetermined sequence, the distance of a canal from the diversion weir and primary canal has certain level of effect on the amount and number of flood turns received by the secondary canal allocated to it.

In Waekel scheme spate water distribution within the canal starts first by drawing lottery among the head, middle and tail sub-groups then continue in sequence. For instance, irrigation could start from the sub groups situated at the head then to the middle and finally to the tail. However, in Weynalem scheme irrigation starts either from the head or tail. The main reason forwarded was starting to irrigate from head or tail of the group highly minimizes wastage of spate water. Spate water will not travel along extended dry canals which would aggravate the wastage of water through seepage before reaching the intended beneficiaries. The farmers in Guguf spate irrigation carry out operation and maintenance works of the diversion weir and diversion and canals in order to effectively use the spate water of the coming rainy season. Then they organize a meeting and perform lottery draw to decide which canal should get the first spate water, the second and so on.

Table 7. Farmers' response to the share of spate water among canals

\begin{tabular}{|c|c|c|c|c|c|c|}
\hline \multirow{3}{*}{$\begin{array}{l}\text { Scheme } \\
\text { Name }\end{array}$} & \multirow{3}{*}{$\begin{array}{l}\text { Canal } \\
\text { Location }\end{array}$} & \multirow{3}{*}{$\begin{array}{l}\text { Number of } \\
\text { Respondents }\end{array}$} & \multicolumn{4}{|c|}{ Equity in spate water share } \\
\hline & & & \multicolumn{2}{|c|}{ Equitable } & \multicolumn{2}{|c|}{ Inequitable } \\
\hline & & & $\mathrm{N}$ & $\%$ & $\mathrm{~N}$ & $\%$ \\
\hline \multirow{4}{*}{ Weynalem } & Head & 10 & 8 & 80 & 2 & 20 \\
\hline & Middle & 9 & 9 & 100 & & \\
\hline & Tail & 9 & 8 & 88.8 & 1 & 11.1 \\
\hline & Total & 28 & 25 & 89.28 & 3 & 10.72 \\
\hline \multirow{4}{*}{ Waekel } & Head & 11 & 10 & 90.9 & 1 & 9.1 \\
\hline & Middle & 11 & 9 & 81.82 & 2 & 18.18 \\
\hline & Tail & 10 & 9 & 90 & 1 & 10 \\
\hline & Total & 32 & 28 & 87.5 & 4 & 12.5 \\
\hline \multirow{4}{*}{ Kusra } & Head & 6 & 4 & 66.67 & 2 & 33.33 \\
\hline & Middle & 6 & 4 & 66.67 & 2 & 33.33 \\
\hline & Tail & 6 & 3 & 50 & 3 & 50 \\
\hline & Total & 18 & 11 & 61.1 & 7 & 38.9 \\
\hline \multicolumn{2}{|c|}{ Grand Total } & 78 & 64 & 82.05 & 14 & 17.95 \\
\hline
\end{tabular}

Source: Survey result, 2018

$\chi^{2}=4.688$ d.f 1 Sig. at $\mathrm{P} \leq 0.05$

The sequence rule is an important rule of water distribution in Guguf spate irrigation system. Groups are liable to get spate water based on a predetermined sequence by the lottery draw. Spate water diverted from the river to the diversion is allocated to the canals based on their sequence. Accordingly, the distribution of spate water for that particular season is decided and groups irrigate their fields based on the established rotation. Table 7 presents the canals at Weynalem, Waekel, and Kusra irrigation schemes arranged based on their distance from the diversion weir and primary canal. The response of sample farmers is assessed with respect to equity of flood received by each group of farmers covered by canals. The fairness of spate water share among branch canals is also evaluated by the farmers as presented in Table 7. 
The result indicates that in Weynalem scheme $80 \%, 100 \%$ and $88 \%$, of the head, middle and tail canals respondents respectively believe that the spate water share is equitable. Only $10.72 \%$ of the scheme respondents replied as there was inequitable distribution of spate flow. In weynalem scheme, the number of head canal respondents replayed equitable distribution $(80 \%)$ was less than (Table 7 ) the middle and tail canal respondents probably due to traditional diversion structures usually do not withstand the heavy floods at the head of the scheme. This is because when the flood is big it usually breaks the side wall of the main canal adjacent to the rivers as a result the flood returns back to the main river. Similarly, in Waekel scheme about $90 \%$ of both head and tail respondents and $81.82 \%$ of the middle branch canal respondents reported there was equitable distribution of spate water. In Kusra scheme about $66 \%$ of the middle and tail canal farmers replied there is equitable share of spate water among canals. However, $50 \%$ of the tail canal respondents replied there is no equity in spate water sharing.

Generally, Table 7 indicated that the farmers (89.28\%) at the canals near to the diversion weir relatively feel that spate water is shared equally among the canals. As the canals become far from the diversion weir the number of respondents $(38.9 \%)$ who feel that spate water is not equally distributed increases. Though there is a sequence rule arrangement in each spate irrigation scheme to ensure fair distribution of spate water among the canals there are situations where the groups near the diversion weir and primary canal benefit more water than the other groups situated far. For instance, small floods that occur at the beginning or at the end of the rainy seasons that are not able to flow far from the primary canals are allocated to serve the nearby groups. In this case though it is not the turn of the group to receive the flood, groups near the primary canal benefit from intermittent floods that fail to reach the group that is waiting its turn. This is believed to make the farmers at relatively far position from the diversion weir to feel there is unequal sharing of spate water.

According to the contacted WMC in Weynalem, Waekel and Kusra schemes small spate flows are diverted to one secondary canal while medium to two and large floods are distributed to all the secondary canals at a time. In the other case the problem in Weynalem scheme is there can be big flood on the river but because of sediment accumulation at the takeoff and along the primary canal the occurrence of big flood to the canals is minimal. If a big flood occurred and supplied flood to all secondary canals and all farm lands in the irrigation system are served, the next spate will be allocated to the waiting group before the occurrence of the big flood. The analysis of Chi-Square test result (Table 7) indicates that there was inequitable distribution of flood water among canals of different schemes. This is consistent to the findings by (Yasew et al. 2014).

3.4 Water right and distribution rules in managing Guguf spate irrigation system

To manage the unpredictable nature of flood water and reduce the risk of conflicts, several categories of water rights and distribution rules are in place in different spate irrigation systems. Even though the community under Guguf River is located at the dry agro-climatic zone, the intensive use of seasonal flood water for spate irrigation enabled the farmers to cope with the arid climate. In using the flood, they gradually developed different traditional and informal water rights and water distribution rules including the rule for operation and maintenance of the spate irrigation system. According to the discussion held with Raya Azebo district Agriculture and Rural Development Office (ARDO) experts and also with the WMC of the schemes considered, the water rights and water distribution rules were not formally prepared in written document. The water rights and water distribution rules are more or less similar to that of developed by (Lawrence, 2005). But not all were established and practiced similarly at all the three schemes (Table 8). 
Table 8. Water right and water distribution rules in Guguf sis schemes

\begin{tabular}{|c|c|c|c|c|c|c|c|}
\hline \multirow[b]{3}{*}{ No } & \multirow{3}{*}{$\begin{array}{l}\text { Water rights and water } \\
\text { distribution rules according } \\
\text { to Lawrence and van Steenbergen } 2005\end{array}$} & \multicolumn{6}{|c|}{ Scheme name } \\
\hline & & \multicolumn{2}{|c|}{ Weynalem } & \multicolumn{2}{|c|}{ Waekel } & \multicolumn{2}{|c|}{ Kusra } \\
\hline & & $\begin{array}{l}\text { Establi } \\
\text { shed }\end{array}$ & $\begin{array}{l}\text { Practi } \\
\text { ced }\end{array}$ & $\begin{array}{l}\text { Establi } \\
\text { shed }\end{array}$ & $\begin{array}{l}\text { Practi } \\
\text { ced }\end{array}$ & $\begin{array}{l}\text { Establi } \\
\text { shed }\end{array}$ & $\begin{array}{l}\text { Practi } \\
\text { ced }\end{array}$ \\
\hline 1 & $\begin{array}{l}\text { Demarcation of land entitled } \\
\text { to irrigation }\end{array}$ & $\checkmark$ & $\checkmark$ & $\checkmark$ & $\checkmark$ & $\mathrm{X}$ & $\mathrm{X}$ \\
\hline 2 & Rules on breaking diversion & & & & & & \\
\hline & Bunds & $\checkmark$ & partial & $\checkmark$ & partial & $\checkmark$ & $\mathrm{X}$ \\
\hline 3 & $\begin{array}{l}\text { Sequence in which the different } \\
\text { fields along a flood watered }\end{array}$ & $\checkmark$ & $\checkmark$ & $\checkmark$ & $\checkmark$ & $\checkmark$ & $\checkmark$ \\
\hline 4 & $\begin{array}{l}\text { Practices regarding second } \\
\text { and third water turns }\end{array}$ & $\checkmark$ & $\checkmark$ & $\checkmark$ & $\checkmark$ & $\checkmark$ & Partial \\
\hline 5 & Rules on small and big floods & $\checkmark$ & $\checkmark$ & $\checkmark$ & partial & $\checkmark$ & $\mathrm{X}$ \\
\hline 6 & $\begin{array}{l}\text { Proportion of the flow going to } \\
\text { different flood channels and } \\
\text { Fields }\end{array}$ & $\checkmark$ & partial & $\checkmark$ & partial & $\checkmark$ & Partial \\
\hline 7 & $\begin{array}{l}\text { The depth of irrigation that each } \\
\text { field is to receive }\end{array}$ & $\checkmark$ & partial & $\checkmark$ & partial & $\checkmark$ & $\mathrm{X}$ \\
\hline
\end{tabular}

Source: Survey result, 2018

Three different implementation modalities were considered (Lawrence and van Steenbergen, 2005): Fully implemented: if the water right and regulation rule was fully practiced in the scheme. Partially implemented: if the water right and rule was partially exercised. Not implemented: if the water right and rule was not practiced. As shown in Table 8, the water right and distribution rule of Guguf spate irrigation was understood similar to the international spate irrigation water right and distribution rule. However, in Guguf water rights and water distribution rules were practiced orally. But all of the listed rules and rights were established and practiced at different levels except in Kusra scheme. According to (van Steenbergen et al., 2011), the rules on breaking bunds are usually in place in areas where the entire ephemeral stream bed is blocked by earthen bunds. The rule on small and high flood; breaking diversion and depth of irrigation that each field is to receive was not implemented in Kusra scheme (lower end of the watershed). While the rule regarding demarcation of land entitled to irrigation is not established and practiced in the scheme. Sequence in which the different fields along a flood watered is the only rule established and implemented in Kusra scheme.

As shown in Table 8, under the Weynalem and Waekel schemes, the rules of sequence in which the different fields along a flood channel were watered, practices regarding second and third water turns, and demarcation of land entitled to irrigation were fully implemented whereas the rule of depth of irrigation that each field receive was partially implemented. According to the interviewed farmers the reason for the complete implementation of the rules was flood keepers who were assigned by WMC and had the responsibility of following the distribution and division of flood water in sequence. The flood keepers were selected from each canal of the diversions. At a time three keepers were assigned to a diversion. The same procured was followed for the other diversions.

According to the discussion held with WMC, the community has unwritten rules (called locally Sirit) to manage the spate irrigation system. The Sirit clearly defines each farmer's right and duties which contribute towards involving every user reasonably. In the study period (2018) the major elements of the Sirit of the study area were: A member who does not participate in silt removing shall pay 50 birr per day; A member who provokes a conflict during spate water distribution shall pay100 birr; A member who insults Abo-Gerebs or AboMais shall be fined 100 birr; A person proved to have stolen water by breaking canal out of his turn and deprived other entitled persons of their share shall pay 3000 birr; After irrigating his land if a farmer does not close his field canals and let other people close the canals for him he will be fined 50 birr; A member who failed to pay his fines and relieve the person who bailed him shall be excluded from the association; A member who repeatedly failed to participate in construction and maintenance of irrigation infrastructures shall be excluded from the association; Members who did not get a single spate water the previous rainy season gets priority in the next season; Money collected in the water users association will be used for drinking when irrigators arrange a convenient day locally called Hirud to indicate day of eating and drinking using the money collected from defaulters.

\section{Conclusion}

Spate irrigation is the diversion of spate floods running off from mountainous catchments, diverted by hydraulic structures and applied to low-lying irrigable fields in arid and semi-arid areas to improve farmers' livelihood. 
This flood based farming requires cohesive institutional arrangements among farmers to divert and manage the distribution of flood flows. The Guguf spate irrigation system is one of the community managed irrigation practices for a long time in Raya Azebo district, Northern Ethiopia. Despite its higher potential to support the livelihood of farmers and achieve food security, spate irrigation has received a little attention. In view of this, the study attempted to examine the distribution of spate water within and among farmers of Weynalem, Waekel and Kusra schemes of the Guguf spate irrigation using descriptive analysis, Chi-square and one-way ANOVA.

The three schemes are diverting the flood water to their respective main diversions from the same riverGuguf. The entire scheme members are required to contribute labor for the maintenance of head work and main canal. The high labor requirement for main diversion and weir maintenance and removing of silt from canals is tiresome. Hence, to ensure more timely maintenance and reduce labor requirement the irrigators in Waekel scheme introduced bulldozers. On the other hand, conveyance structures such as secondary and field canals that serve only to part of the command area are maintained by the individuals using them.

In Guguf spate irrigation, the spate flood is distributed through a well-laid network of primary, secondary and field canals based on the capacity of intake to the primary canal through gated intake. A field of the command area was irrigated in its turn through the canal bund; water is released by breached canal to the downstream field bund to direct water to the next field. This process is repeated until all the fields have been irrigated. The water allocation among the various spate diversion systems constructed along the same river course is based on head to bottom principle and heavily relies on the size of flood. The downstream diversions have greater access to spate water in case of big and medium flood size. If floods are small, diversions at the top and middle of the stream are the beneficiaries. On the other hand, flood distribution among farmers using the same traditional diversion is made through lottery system.

The mean hours farmers irrigated in summer vary significantly ( $\mathrm{p} \leq 0.01)$ among Weynalem, Waekel and Kusra irrigation schemes which mean the distribution of spate water farmers irrigated was inequitable across the schemes of Guguf irrigation system. The findings had revealed that scheme located at the top of the river course received better flood supply than those located at a lower reach. While crops in farms of the lower reach are failing due to insufficient moisture, the top plots are irrigated more than 7 hours. This would obviously explain why the maize in the bottom plot has failed during its initial growth stage. This clearly suggests the unwise utilization of the scarce flood water resource among the top, middle and down schemes. The farmers at the top have better access to the flood water; they spend more time, labor and other resources on their spate fields. In the three schemes there is a local rule on water sharing and distribution, operation and maintenance. The water right and distribution rules were similarly established but differences in implementation were observed among the three schemes. The existing Sirit (local local bylaws) flood size-based distribution favors to farmers at the head of the stream course, if water allocation is made based on crop type and growth stage, even a small flood could be enough to supply water to farms across a water course.

\section{Reference}

Abraham Mehari. 2007. "Water Management Reforms and Indigenous Spate Irrigation.” Wageningen University. Abrha, Misgina. 2006. "An Assessment of Challenges of Sustainable Rural Water Supply: The Case of Ofla Woreda in Tigray Region A Thesis Presented To the School Of Graduate Studies , In P." Addis Ababa University.

Briggs. 2005. "Briggs, J. (2005) The Use of Indigenous Knowledge in Development: Problems and Challenges." Progress in Development Studies 5: 99-114.

David, Wahyudi, and Angelika Ploeger. 2014. "Indigenous Knowledge (IK) of Water Resources Management in West Sumatra, Indonesia.” Future of Food: Journal on Food, Agriculture and Society 2(1): 52-60.

E. N. Ajani, R. N. Mgbenka1 and M. N. Okeke. 2013. "Use of Indigenous Knowledge as a Strategy for Climate Change Adaptation among Farmers in Sub-Saharan Africa: Implications for Policy." Asian Journal of Agricultural Extension, Economics \& Sociology 2(1): 23-40.

FDRE. 2002. "Federal Democratic Republic of Ethiopia Ministry of Water Resource Water Sector Development Program Main Report.” II(October).

Habtu, Solomon, and Kitamura Yoshinobu. 2006. "Traditional Irrigation Management in Betmera-Hiwane, Ethiopia: The Main Peculiarities for the Persistence of Irrigation Practices.” Journal of Mountain Science 3(2): 139-46.

Haile, Abraham Mehari, Abebe DemissieTesfa-alem G. Embaye, Abiti Getaneh et al. 2013. Flood-Based Farming for Livelihoods in Ethiopia Lowlands : Status, Potential and Investment Guide.

Ham, John-Paul van den. 2008. "Dodota Spate Irrigation System Ethiopia A Case Study of Spate Irrigation Management and Livelihood Options."

Israel, Glenn D. 2018. "Sampling the Evidence of Extension Program Impact 1 The Evaluation Purpose Defining the Population." : 1-9. http://edis.ifas.ufl.edu/pd006.

Lawrence, P, van Steenbergen. 2005. Improving Community Spate Irrigation. 
Mehari Haile, Abraham, Bart Schultz, and Herman Depeweg. 2005. "Water Sharing and Conflicts in the Wadi Laba Spate Irrigation System, Eritrea."

Morgan, Te Kipa Kepa Brian et al. 2012. "Indigenous Knowledge Contribution to Watershed Management." The 2012 World Congress on Advances in Civil, Environmental, and Materials Research (ACEM' 12).

Nazari, Bijan, Abdolmajid Liaghat, Mohammad Reza Akbari, and Marzieh Keshavarz. 2018. "Irrigation Water Management in Iran: Implications for Water Use Efficiency Improvement." Agricultural Water Management 208(August): 7-18. https://doi.org/10.1016/j.agwat.2018.06.003.

Negash, Emnet, Girmay Gebresamuel, Tesfa-alem G Embaye, and Amanuel Zenebe. 2019. "The Effect of Climate and Land - Cover Changes on Runoff Response in Guguf Spate Systems, Northern Ethiopia THE EFFECT OF CLIMATE AND LAND-COVER CHANGES ON RUNOFF RESPONSE IN.” (February).

NMA. 2017. The Federal Democratic Republic of Ethiopia Ministry of Water Resource, National Meteorology Agency, Mekele Branch.

van Steenbergen, Frank et al. 2011. "Status and Potential of Spate Irrigation in Ethiopia." Water Resources Management 25(7): 1899-1913.

Wani, Suhas P., A R Maglinao, A Ramakrishna, and T. J. Rego. 2003. Proceedings of ADB- ... Integrated Watershed Management for Land and Water Conservation and Sustainable Agricultural Production in Asia. http://www.sidalc.net/cgiin/wxis.exe/?IsisScript=CIMMYT.xis\&method=post\&formato=2\&cantidad=1\&ex presion $=m f n=038343$.

Yasew, Eyasu et al. 2014. "Spate Irrigation Systems in Raya Valley (Ethiopia)." : 47 pp. www.spateirrigation.org. 